\title{
The Pharmacotherapy of Persistent Genital Arousal Disorder
}

\author{
Tillmann H. C. Kruger ${ }^{1} \cdot$ Cordula Schippert $^{2} \cdot$ Bernhard Meyer $^{3}$
}

Published online: 20 January 2020

(C) The Author(s) 2020

\begin{abstract}
Purpose of Review Persistent genital arousal disorder (PGAD) is a rare, yet debilitating, disease, which was first described at the beginning of this century and has not yet been considered by the ICD-10 or DSM-5. Since affected subjects usually suffer tremendously, this review aims at offering an overview of pharmacological approaches to treat this disorder.

Recent Findings Until now, no randomised placebo-controlled clinical trials have been conducted on PGAD, and the international registries have not recorded any ongoing trials. Current knowledge on pharmacological options for the treatment of PGAD relies mainly on case reports/case series. Most importantly, there is evidence that some drugs such as SSRIs and SNRIs might induce or worsen PGAD.

Summary Knowledge on pharmacological treatment options for PGAD is not yet evidence-based, while some reports even assume an induction of PGAD by serotonergic antidepressants. Nevertheless, practitioners should be aware of PGAD and carefully discuss with the patient an individual treatment trial by considering the experience up to now.
\end{abstract}

Keywords Persistent genital arousal disorder (PGAD) $\cdot$ Sexual arousal $\cdot$ Genital $\cdot$ Drugs $\cdot$ SSRI

\section{Introduction}

Persistent genital arousal disorder (PGAD), also named restless genital syndrome (ReGS) or persistent sexual arousal syndrome (PSAS), is a rare and debilitating disease. The most common term 'PGAD' will be used in the following work. The aetiology and pathogenesis of PGAD are unknown. Hence, we are far from having any concrete ideas about how to effectively help people with PGAD. Nevertheless, a number of open trials, case reports and expert experiences may help the practitioner not only to better identify PGAD but also to initiate pharmacological or non-pharmacological compassionate use. In this review

This article is part of the Topical Collection on Clinical Therapeutics

Tillmann H. C. Kruger

krueger.tillmann@mh-hannover.de

1 Department of Psychiatry, Social Psychiatry and Psychotherapy, Division of Clinical Psychology and Sexual Medicine, Hannover Medical School, Carl-Neuberg Strasse 1, 30625 Hannover, Germany

2 Department of Gynecology and Obstetrics, Hannover Medical School, Carl-Neuberg Strasse 1, 30625 Hannover, Germany

3 Institute of Radiology, Hannover Medical School, Carl-Neuberg Strasse 1, 30625 Hannover, Germany article, I will put an emphasis on the possible risks and benefits of pharmacological treatments.

\section{What Is PGAD and How to Diagnose?}

The supposed symptoms of PGAD were first reported in a paper by Jack G. Modell in 1989 [1], in which a case of a woman is described with repeated yawning, clitoral engorgement and orgasms associated with fluoxetine administration. At the beginning of this century, the term PGAD was then defined by Leiblum and Nathan in women, independent of any drug intake $[2 \cdot]$, and characterised by five diagnostic criteria:

1. Persistence of genital arousal over an extended period of time

2. It is unresolved after one or more orgasms

3. It is unrelated to subjective sexual desires or feelings

4. It is experienced as intrusive and unwanted

5. It causes distress.

These criteria have also been covered by more recent sexual disorder nomenclature and a definition by the International Society for the Study of Women's Sexual Health [3]. PGAD is 
most often observed in women, with few reports in men [4-7], children [8] or adolescents [9]. Further information on the epidemiology, comorbidities, heritability and the course of the disorder is sparse. Representative studies on the prevalence are missing. Surveys of sexual clinics and extrapolations point towards a prevalence between 0.5 and $6.7 \%$ [10••]. For an overview on theories on the causes, pathophysiology and triggers of PGAD, the reader is referred to the review by Jackowich and co-workers [10••]. It is assumed that different pathological factors may lead to PGAD, with all of them involving any kind of affection of the central (brain and spinal cord) and/or peripheral nervous system (pudendal nerve) with states of pathologically increased sensory perception, neuronal hyperexcitability and/or disinhibition $[4,10 \bullet \bullet, 11]$.

From a clinical point of view, persons with suspected PGAD should undergo comprehensive clinical and laboratory investigations with a complete patient history, including sexual and reproductive issues and a careful drug history. Various factors have been associated with the occurrence of PGAD, including Tarlov cysts, pelvic congestion and varices, pelvic injuries or injuries of neural structures, nerve compression, tumours, pudendal neuralgia or other rare peripheral neuropathies (e.g. ilioinguinalis/iliohypogastricus syndrome and spermaticus neuralgia) and restless legs syndrome (see [10••] for review and [12]). Per differential diagnoses, the practitioner should screen for genitopelvic pain disorders, bladder disorders, vulvodynia and somatoform disorders. All of these differential diagnoses occur rarely in those patients that present during our consultation hours after having made a selfdiagnosis according to information obtained from the Internet. The abovementioned factors may lead to additional investigations, including an orientating laboratory assessment; ultrasound examination of pelvic organs and magnetic resonance imaging (MRI) of the pelvis, brain, spinal cord and spinal roots as well as an electroencephalogram. It seems that only few cases depict a specific somatic pathology that might account for PGAD.

\section{What Can Be Done Therapeutically?}

Different therapeutic strategies have been undertaken so far, with rather crude underlying concepts. As not uncommon in rare diseases, there is not a single randomised placebo-controlled clinical trial (RCT) for PGAD, and clinicians usually do an individual pharmacological or non-pharmacological treatment trial with some of them being published as case reports or case series. Most probably, there is an underreporting of treatment failures, which, however, might also provide important information for research and treatment.

With regard to non-pharmacological treatment options, dietary modification and counselling ( $n=1$, soy-based diet); pelvic floor physiotherapy $(n=1)$; transcutaneous electrical nerve stimulation (TENS, $n=4$, one of them without response); transcranial magnetic stimulation (TMS, $n=2$ ); pudendal or sacral neuromodulation $(n=2)$; electroconvulsive therapy (ECT, $n=3$ ); surgical procedures, such as removal of periclitoral mass, clitoridectomy or neurolysis of the dorsal branch of the pudendal nerve $(n=8)$; coil embolisation of a dilated ovarian vein $(n=3)$ and wearing a V-brace $(n=1)$ have been reported as successful in the respective cases (for an overview, see $\left[10^{\bullet}\right]$, as well as [12-14]). From a psychotherapeutic perspective, success with couple therapy and hypnotherapy have been described in one case, respectively [10•0]. A systematic overview of non-successful treatment efforts does not exist.

As there is currently no aetiopathological model of PGAD, there are only crude ideas on pharmacological strategies for PGAD. It has been suggested that it may be due to some kind of central nervous system (CNS) hyperactivity, disinhibition, functional hyperconnectivity between specific brain areas, small fibre neuropathy or psychiatric or neurological comorbidities $[10 \bullet \bullet, 11,15]$. Drugs that have been used to treat PGAD can be categorised into the following groups (see also Table 1):

a) Drugs that increase the inhibitory (most probably serotonergic) tone of the CNS on sexual function, such as the tricyclic antidepressant clomipramine or the serotonin and norepinephrine reuptake inhibitor (SNRI) duloxetine or tramadol.

b) Drugs that antagonise (sexually excitatory) dopamine-2 receptors, such as risperidone or paliperidone.

c) Drugs that downregulate neuronal activity, such as the anticonvulsants carbamazepine (presynaptic sodium channel blocker), pregabalin (presynaptic calcium channel blocker) and topiramate (diverse mechanisms).

d) Drugs that downregulate various structures of the 'sexual brain' as a result of antiandrogen treatment with the gonadotropin-releasing hormone $(\mathrm{GnRH})$ analogue leuprolide.

e) Drugs that alter peripheral/central sensory perception and inflammation via injection of botulinum toxin or intake of tramadol or tetrahydrocannabinol (THC).

Additionally, dopamine agonists have been tried in two cases $[25,26]$, which sounds counterintuitive unless a shared pathophysiology (such as a dopaminergic deficit) with restless legs syndrome or Parkinson disease is assumed. At our institution, dopamine agonists have never been tried as a first-choice treatment, since there are plenty of cases reporting elevated rates of impulse control disorders during L-DOPA and dopamine agonist treatment, including hypersexuality, pathological gambling, compulsive shopping and binge eating $[30 \bullet, 31 \bullet \cdot]$. Thus, pharmacologically increasing the central dopaminergic tone requires sensitive management. 
Table 1 Drugs that have been used to improve PGAD symptoms

\begin{tabular}{|c|c|c|c|}
\hline Drug class & Name & $\begin{array}{l}\text { No. of subjects } \\
\text { reported }\end{array}$ & Clinical effect \\
\hline Antiandrogens & Leuprolide & 1 & Improvement of PGAD [16] \\
\hline \multirow[t]{3}{*}{ Antidepressants } & Clomipramine & 7 & Improvement of PGAD [17] \\
\hline & Duloxetine & 1 (male) & Improvement of PGAD and PE [6] \\
\hline & & 2 & Remission of PGAD $[18,19]$ \\
\hline \multirow[t]{3}{*}{ Anticonvulsants } & Carbamazepine & 1 & Lack of improvement of PGAD [5] \\
\hline & Pregabalin & 3 & $\begin{array}{l}\text { Improvement [18], mild improvement [20] } \\
\text { or improvement of PGAD in combination } \\
\text { with diazepam [21] }\end{array}$ \\
\hline & Topiramate & 2 & Improvement [22] or remission of PGAD [23] \\
\hline $\begin{array}{l}\text { Partial agonist at nicotinic acetylcholine receptor } \\
\text { subtypes for smoking cessation }\end{array}$ & Varenicline & 1 & Improvement of PGAD after 2 weeks [24] \\
\hline \multirow[t]{2}{*}{ Dopamine agonists } & Pramipexole & 1 & Improvement of PGAD and comorbid RLS [25] \\
\hline & & 1 & $\begin{array}{l}\text { Improvement of RGS in a patient with } \\
\text { Parkinson syndrome [26] }\end{array}$ \\
\hline \multirow[t]{2}{*}{ Dopamine antagonists } & Risperidone & 1 & Improvement of PGAD [27] \\
\hline & Paliperidone & 1 & Improvement of PGAD [28] \\
\hline Opioids & Tramadol & 1 & $\begin{array}{l}\text { Improvement of PGAD (unpublished observation } \\
\text { by the author) }\end{array}$ \\
\hline \multirow[t]{2}{*}{ Toxins } & Botulinum toxin & 2 & Improvement of PGAD [29] \\
\hline & & 2 & $\begin{array}{l}\text { Lack of improvement of PGAD } \\
\quad \text { (unpublished observation by the author) }\end{array}$ \\
\hline \multirow[t]{2}{*}{ Cannabinoids } & $\begin{array}{l}\text { Tetrahydrocannabinol } \\
\text { (THC) }\end{array}$ & 1 & $\begin{array}{l}\text { Increased subjective tolerance threshold of } \\
\text { PGAD symptoms } \\
\text { (unpublished observation by the author) }\end{array}$ \\
\hline & Cannabidiol (CBD) & 2 & $\begin{array}{l}\text { Lack of improvement of PGAD (unpublished } \\
\text { observation by the author) }\end{array}$ \\
\hline
\end{tabular}

As outlined in Table 1, there are a small number of individual treatment trials that have used one of the drug classes described above. This includes treatments with antiandrogens $(n=1)$, antidepressants $(n=10)$, anticonvulsants $(n=6$, one without improvement), a partial acetylcholine receptor agonist $(n=1)$, dopamine agonists $(n=2)$, dopamine antagonists $(n=$ $2)$, botulinum toxin as a periclitoral injection treatment $(n=4)$, tramadol $(n=1)$, tetrahydrocannabinol (THC, $n=1)$ or cannabidiol ( $n=2$, without improvement).

\section{Can Drugs Induce PGAD?}

Apart from this limited data on the pharmacotherapy of PGAD, a question of outmost importance is whether the administration or discontinuation of these or other drugs is associated with an induction or worsening of PGAD. A number of reports have clearly suggested such a link. As outlined in Table 2, these drugs again include antidepressants, anticonvulsants and antipsychotics. From a pharmacodynamic point of view, all of them relate in various degrees to the serotonergic system by blocking presynaptic serotonin reuptake transporters and/or antagonising or agonising different postsynaptic serotonin receptors. One recent and extensive investigation acknowledged six cases of PGAD after SSRI treatment (two males, four females) among 300 cases of enduring sexual dysfunction from 37 countries, following different drugs such as SSRIs, $5 \alpha$-reductase inhibitors and isotretinoin and using data from an independent drug safety website (https://rxisk.org/) [34••]. Although not mentioning PGAD, a European Medicine Agency (EMA) warning in 2019 has highlighted the risk of SSRI-induced persistent sexual dysfunction (https://rxisk.org/ema-acknowledges-persistentsexual-dysfunction-after-ssris-snris/). Indeed, for quite some years, there has been a discussion about how SSRIs and $5 \alpha$ reductase inhibitors may induce sexual dysfunction not only during intake but also as a tardive sexual or 'legacy' syndrome (for reviews, see [41••, 42]). In case the serotonin system plays a specific role in PGAD, one of the most important questions now is how serotonergic drugs might be able to sustainably alter this neurotransmitter system (e.g. by influencing pre- and postsynaptic function, receptor up- and downregulation, change of second messengers and change in neuronal structure and function) and how these alterations persist after cessation of treatment. Transporter and receptor imaging studies might yield first evidence in this context. 
Table 2 Drugs that may induce or worsen PGAD symptoms during intake or discontinuation

\begin{tabular}{|c|c|c|c|}
\hline Drug class & Name & No. of subjects reported & Clinical effect \\
\hline \multirow[t]{11}{*}{ Antidepressants } & Citalopram & 3 & Induction of clitoral priapism [32] \\
\hline & Fluoxetine & 1 & $\begin{array}{l}\text { Induction of yawning, clitoral [1], engorgement } \\
\text { and orgasm }\end{array}$ \\
\hline & Venlafaxine & 1 & Induction of PGAD [33] \\
\hline & Different SSRIs & $\begin{array}{l}6 \text { out of } 300 \text { cases with enduring sexual } \\
\text { dysfunction } \\
(2 \text { males, } 4 \text { females })\end{array}$ & Induction of PGAD [34] \\
\hline & Citalopram (SSRI) & 1 & PGAD induction by withdrawal [35] \\
\hline & Fluvoxamine (SSRI) & 1 & PGAD induction by withdrawal (Kruger 2018) \\
\hline & Milnacipran (SNRI) & 1 & RGS induction by withdrawal [36] \\
\hline & Paroxetine (SSRI) & 1 & PGAD induction by withdrawal [37] \\
\hline & $\begin{array}{l}\text { Venlafaxine (3), sertraline (1), } \\
\text { fluoxetine (1) }\end{array}$ & 5 out of 364 (web survey) & PGAD induction by withdrawal [38] \\
\hline & Various SSRIs & 10 out of 15 & PGAD induction by withdrawal [39] \\
\hline & Various SSRIs & 23 out of 115 (online sample) & PGAD induction by withdrawal [8] \\
\hline Anticonvulsants & Lamotrigine & 1 & PGAD induction [40] \\
\hline Antipsychotics & Quetiapine & 1 & PGAD induction [33] \\
\hline
\end{tabular}

\section{Conclusions and Recommendations}

The pharmacotherapy of PGAD is a tricky thing. There is a paucity of controlled data, knowledge merely relies on case reports and there is evidence that a number of drugs with serotonergic properties can induce PGAD during intake or discontinuation of the drug. As it is often the case in rare or only recently described diseases, the aetiology is unknown and pathophysiological theories are rare and appear weak due to missing scientific data. Therefore, pharmacotherapy lacks a solid basis. However, therapeutic nihilism will not aid any patient, and there are some cases in which treatment with an anticonvulsant or SNRI has led to substantial improvement (see Table 1). Nevertheless, we should keep in mind that SSRIs and SNRIs are most clearly related to sexual dysfunction - not only during intake but sometimes even persisting after drug discontinuation, which is discussed as post-SSRI sexual dysfunction (PSSD) [43].

Apart from pharmacotherapy, we should treat our patients in a comprehensive way and keep in mind a number of other treatment options briefly mentioned above. As soon as diagnostic procedures have been finished and a somatic reason excluded, I usually offer a 3-column approach incorporating (1) pharmacotherapy, (2) physiotherapy of the pelvis and (3) psychotherapy/counselling. Patients often feel ashamed of their symptoms, and some of them have had negative experiences when presenting their symptoms to medical doctors that are unaware of PGAD. Therefore, I hope to increase the awareness of a rare disease with this paper. Clinicians should keep in mind (a) a proper diagnostic procedure; (b) that men, children and adolescents may also suffer from PGAD and (c) that some form of treatment deserves a trial after a careful riskbenefit analysis and shared decision-making with the patient.

\section{Clinical Vignette}

The 17-year-old teenager nullipara initially presented with sensations of genital arousal which started 5 weeks ago without perceiving subjective sexual arousal. She localised the sensations in the area of the clitoris, slightly left accentuated, and perceived this as highly disturbing. The intensity of symptoms was rated at 9 of 10 on a visual analogue rating scale (VAS). Sometimes she also had sensations of pressure, swelling and tingling in her clitoris whereas vaginal lubrication was not observed. She did not have spontaneous orgasms but sometimes a feeling of being just before an orgasm and/or urinary urgency. Before first occurrence of symptoms, she had taken ibuprofen three times $400 \mathrm{mg}$ due to a cold. During intake of this medication, she also recognised having sexual phantasies. As current trigger factors, she reported straight sitting and laying down in a lateral position or having crossed her legs. Sleep disturbances did not occur.

She presented herself to her gynaecologist and made some internet research regarding her symptoms. Her gynaecologist and herself then discussed PGAD as a possible cause. While waiting for the first appointment in our sexual medicine department, the gynaecologist initiated a treatment trial with pregabalin in a low dose of $3 \times 25 \mathrm{mg}$ per day. During this treatment, her symptoms decreased in intensity from 9 to $4 / 10$ on the VAS.

During the first consultation at $\mathrm{MHH}$, she and her parents were very concerned about the disease. A careful psychiatric and sexual medicine history was taken and differential diagnoses such as somatoform disorders were excluded. We decided to continue the medication with pregabalin and to further increase it. She tolerated a dose of $200 \mathrm{mg}$ per day while 
fatigue increased with higher doses. Symptoms never fully disappeared. The patient also initiated physiotherapy (improvement of pelvic floor strength and relaxation) and a psychotherapy without substantial effect on genital symptoms.

Subsequently, clinical investigations including MRI of pelvis and spinal cord, ultrasound of the pelvis, neurophysiological measures and basic laboratory assessments were initiated. MRI of the pelvis and MR angiography revealed a pelvic venous congestion syndrome with a pronunciation of the left side and early venous filling of the venous convolute located superior of the left ovary. No obvious disturbance of the pudendal nerve was seen including assessment of Alcock's canal. After careful discussion of findings with an interventional radiologist, the patient and her parents decided to undergo a two-stage angiographic embolisation of respective vessels in $11 / 2018$ and 10/2019. During the first intervention, patient reported about a local increase of the symptoms during contrast injection into the ectatic pelvic veins; genital symptoms slightly improved after the first intervention. Thus, a second embolisation of residual veins was conducted. After these interventions, the maintained perfusion of ovarian blood vessels was confirmed, so reduction of ovarian function is not suspected. Clinical evaluation of the second intervention will be carried out in 3 and 6 months. Currently, the patient is still taking 75-mg pregabalin per day; symptom severity is between 3 and 4/10. In contrast to the beginning of symptoms, she is able to go to school on a regular basis and rates her general life quality as moderate to good. Nevertheless, depending on the outcome of the second intervention, she still seeks for a definite treatment of her PGAD.

This case illustrates that patients with putative PGAD may extremely suffer and try to find a doctor who might know such kind of symptoms. The aetiology of PGAD remains unclear in this case. There is a co-occurrence of initial PGAD symptoms with intake of ibuprofen which, however, was not yet reported in the literature as putative cause of PGAD. Later, MRI of the pelvis revealed a pelvic congestion syndrome with a left-sided pronunciation and in the vicinity of the left ovary. This was in correspondence with left-sided accentuated clinical symptoms. However, there was no constriction of the pudendal nerve which might explain the very distinct symptoms restricted to the clitoris. Furthermore, transarterial embolisation of the respective veins did not lead to a sufficient improvement yet. Alternatively, pregabalin might have led to some improvement although it seemed that both dosages $(75 \mathrm{mg}$ and $300 \mathrm{mg}$ /day) had the same effect. As a conclusion, more questions than answers remain with this case. However, the patient and her parents are extremely thankful for any help and for having found experts knowing this rare disease. An interdisciplinary approach is mandatory. In light of missing controlled data, a very careful risk-benefit analysis with the patient and shared decision-making are mandatory whenever a pharmacological or surgical/angiographic intervention is planned.
Funding Information Open Access funding provided by Projekt DEAL. Writing of this paper was partly supported by a European Society for Sexual Medicine (ESSM) research grant (grant 15-20).

\section{Compliance with Ethical Standards}

Conflict of Interest Tillmann H.C. Kruger has worked as a lecturer and/ or consultant in the past 12 months for Allergan, Ipsen, Lilly, Lundbeck, Novartis, Otsuka, Schwabe and Trommsdorf.

Cordula Schippert and Bernhard Meyer each declare no conflict of interest.

Human and Animal Rights and Informed Consent This article does not contain any studies with human or animal subjects performed by any of the authors.

Open Access This article is licensed under a Creative Commons Attribution 4.0 International License, which permits use, sharing, adaptation, distribution and reproduction in any medium or format, as long as you give appropriate credit to the original author(s) and the source, provide a link to the Creative Commons licence, and indicate if changes were made. The images or other third party material in this article are included in the article's Creative Commons licence, unless indicated otherwise in a credit line to the material. If material is not included in the article's Creative Commons licence and your intended use is not permitted by statutory regulation or exceeds the permitted use, you will need to obtain permission directly from the copyright holder. To view a copy of this licence, visit http://creativecommons.org/licenses/by/4.0/.

\section{References}

Papers of particular interest, published recently, have been highlighted as:

- Of importance

•- Of major importance

1. Modell JG. Repeated observations of yawning, clitoral engorgement, and orgasm associated with fluoxetine administration. $J$ Clin Psychopharmacol. 1989;9:63-5.

2. •. Leiblum SR, Nathan SG. Persistent sexual arousal syndrome: a newly discovered pattern of female sexuality. J Sex Marital Ther. 2001;27:365-80 one of the first scientific descriptions of PGAD.

3. Parish SJ, Goldstein AT, Goldstein SW, Goldstein I, Pfaus J, Clayton $\mathrm{AH}$, et al. Toward a more evidencebased nosology and nomenclature for female sexual dysfunctions-Part II. J Sex Med. 2016;13:1888-906.

4. Waldinger MD, Venema PL, van Gils AP, de Lint GJ, Schweitzer DH. Stronger evidence for small fiber sensory neuropathy in restless genital syndrome: two case reports in males. J Sex Med. 2011;8:325-30.

5. Kamatchi R, Ashley-Smith A. Persistent genital arousal disorder in a male: a case report and analysis of the cause. Br J Med Psychol. 2013;6:30-1.

6. Kruger TH, Hartmann U. A case of comorbid persistent genital arousal disorder and premature ejaculation: killing two birds with one stone. J Sex Marital Ther. 2016;42:1-3.

7. Stevenson BJ, Kohler TS. First reported case of isolated persistent genital arousal disorder in a male. Case Rep Urol. 2015;2015: 465748 . 
8. Jackowich R, Pink L, Gordon A, Poirier É, Pukall CF. Symptom characteristics and medical history of an online sample of women who experience symptoms of persistent genital arousal. J Sex Marital Ther. 2018;44:111-26.

9. Curran KA. Case report: persistent genital arousal disorder in an adolescent woman. J Pediatr Adolesc Gynecol. 2019;32:186-8.

10. • Jackowich RA, Pink L, Gordon A, Pukall CF. Persistent genital arousal disorder: a review of its conceptualizations, potential origins, impact, and treatment. Sex Med Rev. 2016;4:329-42 provides a very good overview on PGA $D$.

11. Kruger THC. Can pharmacotherapy help persistent genital arousal disorder? Expert Opin Pharmacother. 2018;19:1705-9.

12. Klifto K, Dellon AL. Persistent genital arousal disorder: treatment by neurolysis of dorsal branch of pudendal nerve. Microsurgery. 2019. https://doi.org/10.1002/micr.30464.

13. Gaines N, Odom BD, Killinger KA, Peters KM. Pudendal neuromodulation as a treatment for persistent genital arousal disorder-a case series. Female Pelvic Med Reconstr Surg. 2018;24:e1-5.

14. Jones CL, Fischer JR, Hernandez SL. Sacral neuromodulation for the treatment of persistent genital arousal disorder. Obstet Gynecol. 2016;128:321-3.

15. Goldmeier D, Mears A, Hiller J, Crowley T. Persistent genital arousal disorder: a review of the literature and recommendations for management. Int J STD AIDS. 2009;20:373-7.

16. Sforza E, Hupin D, Roche F. Restless Genital Syndrome: Differential Diagnosis and Treatment With Pramipexole. J Clin Sleep Med. 2017;13(9):1109-10. https://doi.org/10.5664/jcsm. 6736.

17. Aquino CC, Mestre T, Lang AE. Restless genital syndrome in Parkinson disease. JAMA Neurol. 2014;71:1559-61.

18. •. Moore TJ, Glenmullen J, Mattison DR. Reports of pathological gambling, hypersexuality, and compulsive shopping associated with dopamine receptor agonist drugs. JAMA Intern Med. 2014;174:1930-3 valuable report on side effects of dopamine agonists on sexual functions.

19. •. Corvol JC, Artaud F, Cormier-Dequaire F, Rascol O, Durif F, Derkinderen $\mathrm{P}$, et al. Longitudinal analysis of impulse control disorders in Parkinson disease. Neurology. 2018;91:e189-201 valuable report on side effects of dop amine agonists on sexual functions.

20. ••. Healy D, Le Noury J, Mangin D. Enduring sexual dysfunction after treatment with antidepressants, $5 \alpha$-reductase i nhibitors and isotretinoin: 300 cases. Int J Risk Saf Med. 2018;29:125-34 valuable report on rare and enduring side effects of antidepressants on sexual functions.

21. ••. Bala A, Nguyen HMT, Hellstrom WJG. Post-SSRI sexual dysfunction: a literature review. Sex Med Rev. 2018;6:29-34 valuable report on rare and enduring side effects of antidepressants on sexual functions.

22. Giatti S, Diviccaro S, Panzica G, Melcangi RC. Post-finasteride syndrome and post-SSRI sexual dysfunction: two sides of the same coin? Endocrine. 2018;61:180-93.

23. Ben-Sheetrit J, Aizenberg D, Csoka AB, Weizman A, Hermesh H. Post-SSRI sexual dysfunction: clinical characterization and preliminary assessment of contributory factors and dose-response relationship. J Clin Psychopharmacol. 2015;35:273-8.

24. Deka K, Dua N, Kakoty M, Ahmed R. Persistent genital arousal disorder: successful treatment with leuprolide (antiandrogen). Indian J Psychiatry. 2015;57:326-8.
25. Yildirim EA, Hacioglu Yildirim M, Carpar E, Sarac I. Clomipramine trial for treatment-resistant persistent genital arousal disorder: a case series. J Psychosom Obstet Gynaecol. 2017;38: 260-7.

26. Philippsohn S, Kruger TH. Persistent genital arousal disorder: successful treatment with duloxetine and pregabalin in two cases. J Sex Med. 2012;9:213-7.

27. Gunduz N, Polat A, Turan H. Persistent genital arousal disorder treated with duloxetine: a case report. Turk Psikiyatri Derg. 2019;30:67-70.

28. Aswath M, Pandit LV, Kashyap K, Ramnath R. Persistent genital arousal disorder. Indian J Psychol Med. 2016;38:341-3.

29. Cohen SD. Diagnosis and treatment of persistent genital arousal disorder. Rev Urol. 2017;19:265-7.

30. Ramic M. A case of persistent genital arousal disorder successfully treated with topiramate in a physically healthy individual. J Clin Psychiatry. 2013;74:693.

31. Anzellotti F, Franciotti R, Bonanni L, Tamburro G, Perrucci MG, Thomas A, et al. Persistent genital arousal disorder associated with functional hyperconnectivity of an epileptic focus. Neuroscience. 2010;167:88-96.

32. Korda JB, Pfaus JG, Goldstein I. Persistent genital arousal disorder: a case report in a woman with lifelong PGAD where serendipitous administration of varenicline tartrate resulted in symptomatic improvement. J Sex Med. 2009;6:1479-86.

33. Wylie K, Levin R, Hallam-Jones R, Goddard A. Sleep exacerbation of persistent sexual arousal syndrome in a postmenopausal woman. J Sex Med. 2006;3:296-302.

34. Fountoulakis KN, Tegos T, Goulis DG, Nimatoudis I, Kimiskidis V. Treatment of a female patient with persistent genital arousal and Parkinson's disease with paliperidone. Aust N Z J Psychiatry. 2017;51:98-9.

35. Nazik H, Api M, Aytan H, Narin R. A new medical treatment with botulinum toxin in persistent genital arousal disorder: successful treatment of two cases. J Sex Marital Ther. 2014;40:170-4.

36. Berk M, Acton M. Citalopram-associated clitoral priapism: a case series. Int Clin Psychopharmacol. 1997;12:121-2.

37. Mahoney S, Zarate C. Persistent sexual arousal syndrome: a case report and review of the literature. J Sex Marital Ther. 2007;33:6571

38. de Magalhaes FJ, Kumar MT. Persistent genital arousal disorder following selective serotonin reuptake inhibitor cessation. J Clin Psychopharmacol. 2015;35:352-4.

39. Miyake K, Takaki M, Sakamoto S, Kawada K, Inoue S, Yamada N. Restless genital syndrome induced by milnacipran. Clin Neuropharmacol. 2018;41:109-10.

40. Eibye S, Jensen HM. Persistent genital arousal disorder: confluent patient history of agitated depression, paroxetine cessation, and a tarlov cyst. Case Rep Psychiatry. 2014;2014:529052.

41. Leiblum SR, Goldmeier D. Persistent genital arousal disorder in women: case reports of association with anti-depressant usage and withdrawal. J Sex Marital Ther. 2008;34:150-9.

42. Freed L. Persistent sexual arousal syndrome. J Sex Med. 2005;2: 743.

43. Calabro RS. Lamotrigine-induced persistent genital arousal disorder: an unusual side effect. Epilepsy Behav. 2017;68:234-5.

Publisher's Note Springer Nature remains neutral with regard to jurisdictional claims in published maps and institutional affiliations. 